\title{
Science outreach in the post-truth age
}

\author{
Outreach activities, like those related to National Nanotechnology Day, contribute to building a science \\ culture, narrowing the gap between science and the public.
}

The definition of 'post-truth' given by Oxford Dictionaries is: "Relating to or denoting circumstances in which objective facts are less influential in shaping public opinion than appeals to emotion and personal belief." There is no better expression to describe the current political climate, and in fact its usage spiked during the months leading up to the Brexit referendum in the UK and to the presidential election in the USA, earning the status of "word of the year 2016. The increasingly common attitude of scepticism towards science can also be considered as an example of post-truism, a point made by Sue Desmond-Hellmann, CEO of the Bill \& Melinda Gates Foundation, in a lecture delivered at Cambridge University (available at http://go.nature.com/2flKfFf). Often in discussions about climate change, vaccination, evolution and homeopathy, to name a few, scientific evidence is belittled in the name of other types of belief.

Denial of scientific theories, without the support of experimental evidence to disprove them, is not new. But what is alarming today is the rise of populist leaders who are endorsing these positions, delegitimizing the advice of experts and reducing it to an opinion as valuable as any other. The problem arises when those same leaders are the ones that should implement regulations and policies in support of scientific progress, and who should fund and promote scientific research to preserve the health and safety of the planet and its inhabitants.

The disingenuous misconstruction of scientific facts (see Chris Toumey's Thesis on page 934 for a deeper analysis on this topic) is, however, only part of the problem. In many cases, scientists also bear some responsibility for the public mistrust towards science when they fail to effectively communicate their discoveries and the impact these have on society.

Take nanotechnology: most people do not realize that it is already part of our everyday lives. It's in our phones, sunscreens, clothes and waterproof shoes. Similarly, they do not realize how big a role it will play in tackling societal challenges such as energy, health, the environment and food supplies. The problem is well known to the National Nanotechnology Coordination Office (NNCO), the White House-led office that coordinates and supports, through federal funding, the National Nanotechnology Initiative (NNI), an $R \& D$ venture that groups 20 different departments and agencies in the field of nanotechnology. Among the NNI's goals, education and outreach are high on the list. For this reason, last year they launched the first National Nanotechnology Day on 9 October (following the American date notation, $10 / 9$, for $\left.10^{-9}\right)$. Several colleges and universities across the country, as well as science foundations and societies, participated in the event with outreach activities, seminars, talks, photography exhibitions and lab visits aimed at filling the gap between the science carried out in the lab and the lay audience's experience of it. Scientists and experts in the field also recorded short 'Nano Nuggets' videos, talking about their vision for nanotechnology. The whole event list is hosted on the NNI website (http://go.nature.com/2wJjYmU) and their YouTube channel

(http://go.nature.com/2xl3zHl). After a successful debut, National Nanotechnology Day will run again this year, with several community-led activities being held in schools, labs and institutes. Student committees have set up many of this year's activities, as described in our In the Classroom column on page 1016. Although the NNCO does not organize the activities themselves, it invites all the participants to send them their plans for the day, describing the events they are involved in and posting videos and pictures to commemorate the day.

\section{"Scientists bear some responsibility for public mistrust when they fail to communicate their discoveries."}

Scientists and researchers can, and should, make their voices heard and defend centuries of research and discoveries in marches and debates,

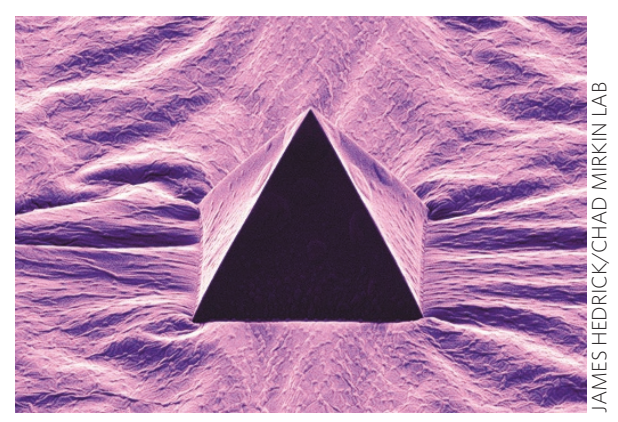

The image above represents a pyramidal tip from an array used for soft lithography. The pyramid is made of a polymeric elastomer coated in glass; cooling the material during the manufacturing process shrinks the polymer, rippling the surface around the tip. The image was recorded at the Northwestern University Atomic and Nanoscale Characterization Center (NUANCE) and exposed with the title 'Lone Glass Pyramid' at the NUANCE Center Fall 2016 Gallery. The gallery's reception was held in occasion of National Nanotechnology Day 2016.

whenever there is a good occasion. But they can also engage with the public and the society in a subtler and more systematic way, promoting science education at all levels and communicating science at schools, science festivals and more informal settings. This seems especially important now when the academic scientific world is in turmoil at the prospect of further budget cuts worldwide, and when science education appears to be threatened by ad hoc variations of the science curriculum. To cite a specific example, New Mexico have recently announced plans to 'soften' the evolution and climate change chapters of the Next Generation Science Standards, a set of national guidelines for middle school students. Outreach activities such as the ones organized for National Nanotechnology Day may be small drops in the ocean, but they can influence the degree of science literacy among the public and foster a science culture that might eventually impact people's choices when it comes to elect their representatives, and demand for fact-based science policies and for fairer funding strategies. 